\title{
State-Wide Outcomes in Elective Rectal Cancer Resection: Is there a case for centralisation in Victoria?
}

\author{
Michael K-Y Hong, DMedSc, FRACS ${ }^{a, b}$ \\ Justin M C Yeung, DM, FRCSEd (General Surgery, FRACS) ${ }^{a, b}$ \\ David A Watters, FRACS ${ }^{\mathrm{C}}$ \\ Ian G Faragher, FCSSANZ, FRACS ${ }^{a, b}$ \\ ${ }^{a}$ Colorectal Surgery Unit, Western Health, Melbourne, Australia \\ ${ }^{b}$ Department of Surgery (Western Health), University of Melbourne, Melbourne, \\ Australia \\ 'Department of Surgery, The Geelong Hospital, Deakin University, Geelong, Victoria, \\ Australia
}

Short title: Outcomes in Rectal Cancer Surgery

Conflicts of Interest: none

Figures: 3

Tables: 1

Supplementary Tables: 1

Word Count (abstract): 243

Word Count (manuscript): 1916

Corresponding Author:

Michael Hong

Honorary Fellow, University of Melbourne (Western Health)

Colorectal and General Surgery Unit, Western Health

E: Michael.Hong@wh.org.au

This is the author manuscript accepted for publication and has undergone full peer review but has not been through the copyediting, typesetting, pagination and proofreading process, which may lead to differences between this version and the Version of Record. Please cite this article as doi: $10.1111 /$ ans.15546

This article is protected by copyright. All rights reserved. 
This article is protected by copyright. All rights reserved. 


\section{Abstract}

Introduction: The role of service centralisation in rectal cancer surgery is controversial. Recent studies suggest centralisation to high volume centres may improve postoperative mortality. We used a state-wide administrative dataset to determine the inpatient mortality for patients undergoing elective rectal cancer surgery and to compare individual hospital volumes.

Methods: The Victorian Admitted Episodes Dataset was explored using the Dr Foster Quality Investigator Tool. The inpatient mortality rate, 30-day readmission rate and the proportion of patients with increased length of stay were measured for all elective admissions for rectal cancer resections between 2012 and 2016. A peer group of 14 hospitals were studied using funnel plots to determine inter-hospital variation in mortality. Procedure types were compared between the groups.

Results: There were 2241 elective resections performed for rectal cancer in Victoria over four years. The crude inpatient mortality rate was $1.1 \%$. There were no significant differences in mortality among 14 hospitals within the peer group. The number of elective resections over 4 years ranged from 14 to 136 (median 65) within these institutions. Ultralow anterior resection was the commonest procedure performed.

Conclusion: Inpatient mortality after elective rectal cancer surgery in Victoria is rare and compares favourably internationally. Based on inpatient mortality alone, there is no compelling evidence to further centralise elective rectal cancer surgery in Victoria. More work is needed to develop datasets with oncological information capable of 
providing accurate complete state-wide data which will be essential for future service planning, training and innovation.

Key Words: rectal cancer, proctectomy, outcomes, administrative data, mortality

This article is protected by copyright. All rights reserved. 


\section{Introduction}

Elective surgery for rectal cancer is complex and challenging. Decision-making in choice of upfront treatment modalities, surgical options and adjuvant care requires a multidisciplinary meeting for optimal outcomes[1, 2]. Several studies have reported a significant association between high hospital volumes and lower mortality[3-8], while others have not found an association[9, 10]. One such study from France recommended centralisation of rectal cancer surgery to improve postoperative mortality rates[5].

In Australia and New Zealand, rectal cancer surgery is increasingly performed by trained subspecialist colorectal surgeons. Studies have shown superior outcomes in rectal cancer surgery performed by subspecialist trained surgeons compared with those without subspecialty training[11, 12]. In addition, individual surgeon procedure volumes also appear to influence outcomes. The exact thresholds for both hospitals and individual surgeons remain uncertain.

A number of datasets capable of providing procedure volumes and outcomes in rectal cancer surgery exist. The Bi-National Colorectal Cancer Audit (BCCA) relies on surgeon uptake and self-reporting, but it is able to provide detailed outcomes and individual surgeon volumes[13]. Administrative datasets do not rely on self-reporting, and are therefore less prone to bias. They provide hospital volumes, but not those of individual surgeons. Using state-wide administrative data, we have previously

This article is protected by copyright. All rights reserved. 
demonstrated the inpatient mortality rate for elective colon cancer resections in Victoria to be $1.3 \%$ over four years[14].

In this study, we aimed to measure the inpatient mortality rate for rectal cancer surgery using a state-wide administrative database. A peer group of 14 hospitals were studied to investigate potential variations in the quality of care as measured by inpatient mortality rates, length of stay and unplanned readmissions and whether these are influenced by procedure volumes. Such findings may have implications for the future planning of rectal cancer services and possible centralisation of rectal cancer surgery.

\section{Methods}

All elective admissions for rectal cancer surgery between $1^{\text {st }}$ July 2012 and $30^{\text {th }}$ June 2016 were extracted from the Victorian Admitted Episodes Dataset (VAED). This cohort was defined using a combination of diagnostic codes from the International Classification of Diseases $10^{\text {th }}$ Revision Australian Modification (ICD-10-AM) and procedure codes from the Australian Classification of Health Interventions (ACHI). These codes included rectal cancer diagnostic codes and proctectomy procedure codes (Supplementary Table 1). Hartmann's and high anterior resection procedure codes were included in combination with rectal cancer diagnoses. Any rectosigmoid cancer diagnoses were not included in the cohort. Coding for the use of a loop

This article is protected by copyright. All rights reserved. 
ileostomy in conjunction with an anterior resection was not available to allow comparison of temporary stoma rates between groups.

The $\mathrm{Dr}$ Foster Quality Investigator Tool was used to interrogate the administrative dataset. This tool, provided by Dr Foster (Telstra Health), was designed to assist healthcare organisations to improve clinical quality through measurement, comparison and benchmarking of administrative data. The primary outcome measured was crude inpatient mortality rate. No data linkage was available to determine 30-day mortality. Readmissions within 30 days were defined as any admission, to any hospital in Victoria, within 30 days of discharge. Readmissions were allocated to the hospital performing the primary surgery. Prolonged LOS was defined as the upper quartile for the LOS. Within the defined cohort, outcomes were measured for public and private hospitals. Fourteen of a possible 22 public health services gave permission to be part of a peer group for comparison of individual hospital outcomes.

Risk adjustment was performed using logistic regression to allow fair comparison between various cohorts for mortality. Factors used for the adjustment included age, gender, Charlson comorbidity score, admission source, number of emergency admissions in prior 12 months, patients under palliative care, and month and year of admission. The benchmark year used for risk modelling was July 2013 to June 2014.

This article is protected by copyright. All rights reserved. 
All statistical analysis was performed with the Dr Foster Quality Investigator Tool. Chi-squared tests were used for proportions. Differences in comparisons were considered significant where the probability was less than 0.05 . A funnel plot was used to explore interhospital variation within the peer group of hospitals for inpatient mortality rate. Confidence levels of $95 \%$ and $99.8 \%$ were highlighted in this plot. Outliers were defined as those outside the $95 \%$ confidence level. This project was approved by the Office of Research, Western Health (QA2017.46), and endorsed by the Dr Foster Intelligence Clinical Focus Group steering committee.

\section{Results}

There were 2241 elective rectal resections performed over 4 years in Victoria between $1^{\text {st }}$ July 2012 and $30^{\text {th }}$ June 2016 (Table 1). The mean age of the overall cohort was 65 years. Approximately half of all rectal resections were performed in the private setting, and the peer group of hospitals accounted for $82 \%$ of the cases performed in a public hospital. The overall crude inpatient mortality rate was 1.1\% (Figure 1).

The mortality rate was $1.0 \%$ in the 14 -hospital peer group and $1.2 \%$ in the private hospitals, with no significant difference between the two $(p=0.71)$. Within the peer group, there was no significant variation between the rates of inpatient mortality, even after risk adjustment (Figure 2). The median LOS for elective rectal resections was 10 days, which was similar throughout the hospitals. The proportion of patients with prolonged LOS was similar among hospitals. There were statistically

This article is protected by copyright. All rights reserved. 
significant differences in the 30-day readmission rates between public and private hospitals ( $15 \%$ vs $6.4 \%, p<0.05$ ), as well as hospitals within the peer group, after risk adjustment.

Volumes of elective rectal cancer resections varied between the peer group hospitals with the least prolific hospital performing 15 resections over 4 years, and the most prolific performing 136 in the same time period. The median number of resections for each peer group hospital was 65 over 4 years. There did not appear to be any correlation between hospital volume and inpatient mortality.

Ultralow anterior resection was the most commonly performed elective operation for rectal cancer over four years. The proportion of operation types for rectal cancer was similar between the peer group and the remainder of the cohort (Figure 3). The overall stoma rate was at least $29 \%$.

\section{Discussion}

Early survival after surgery is an indicator of quality which can be used to compare outcomes between institutions. Our study has demonstrated that the overall inpatient mortality rate in Victoria was $1.1 \%$ in 2241 elective rectal cancer resections over 4 years. This was across all institutions with no significant variation amongst a peer group of hospitals. This rate is similar to that reported by the Bi-National Colorectal Cancer Audit, (BCCA), which includes resections from Australia and New Zealand (1.2\%)[13]. The Queensland Colorectal Cancer Audit, using linkage between

This article is protected by copyright. All rights reserved. 
administrative and clinical databases, found a state-wide inpatient mortality rate of $0.9 \%$ in 656 resections across one year[15]. The 30-day mortality rate remained the same at $0.9 \%$.

Our data on mortality rates also compare favourably with published international figures. A nationwide study from France in over 45000 rectal cancer resections found the 90 -day mortality to be $1.9 \%$ in high volume centres, as opposed to $5.6 \%$ in low volume centres[5]. A study from Ireland on 447 resections found a mortality rate of $1.1 \%$ after centralisation of rectal cancer services. [16]. A Dutch study found a 30-day mortality rate of $2.6 \%$ in 2095 rectal cancer resections, with no effect of hospital volume[10]. Similarly, a Spanish study found a 30-day mortality rate varied between $1.4 \%$ and $2 \%$ with an average of $1.8 \%$, also with no correlation with hospital volume.

The issue of service centralisation is complex. Concentrating experience in high volume centres where there is increased familiarity seems to make sense. The nationwide study from France defined a high volume centre as performing 40 rectal resections per year, whereas others have defined this as many as 60 resections per year[7]. However, the number of elective rectal cancer resections in Victorian peer group hospitals ranged from 14 to 136 (median 65) over four years. None of the hospitals in Victoria meet this definition of a high volume centre. In addition, despite the large variation in volume of resections between hospitals, there was no 
relationship between volume and mortality, length of stay or spread of operation type.

One possible explanation for the low mortality rate and similar outcomes between centres is that within Australia, many surgeons routinely work in more than one institution. Training towards colorectal subspecialisation is well embedded, with most colorectal surgeons being a member of the Colorectal Society of Australia and New Zealand (CSSANZ) and have gone through a General Surgery training programme, followed by colorectal fellowships, a model that is becoming more popular in countries like the United Kingdom[17]. Although the total number of rectal resections may seem small within each institution, surgical and perioperative treatment are consultant-led. Many of our surgeons and senior clinicians work between several of the analysed hospitals, including some of the low-volume centres.

Another possible explanation is that informal centralisation is already happening in Victoria. Clinicians may already be referring more complex procedures to higher volume metropolitan institutions and quaternary centres. The availability and experience of multidisciplinary care at these institutions could impact on the care of these patients[18]. Poised against this is that in Australia, there are often vast distances between health services, a reality that is not found in some European countries[19]. When one considers these geographical challenges together with a currently low inpatient mortality rate, there does not appear to be any compelling reason to alter the current pattern of elective rectal cancer surgery in Victoria.

This article is protected by copyright. All rights reserved. 
The impact of service centralisation or maintaining the current pattern of service includes those on surgical training as well as innovation. At least half of all rectal resections were performed privately in Victoria, and in one public hospital only 14 cases were performed over 4 years. Considering these figures, surgical exposure and training will need to be carefully mapped out; with a greater emphasis on rotating trainees to centres with sufficient numbers for training. Concentrating rectal cancer surgery in fewer centres potentially delivers better training but to fewer surgeons. In addition, it may allow a stronger foundation for emerging surgical innovation and telemedicine. Finally there is also evidence that many patients prefer to have their treatment provided within their local vicinity; another reason to defer the centralisation of care[19].

The most significant limitation in our study was the lack of oncological information. Such information could be used as other quality indicators, including treatment intention, use of neoadjuvant treatments, use of minimally-invasive techniques, complications, cancer stage, lymph node yield, margin positivity, local recurrence rates and 5-year survival. Multiple datasets for colorectal cancer exist, many with such information, but most are incomplete due to variation in uptake and reliance on self-reporting. The yield from these datasets can be improved by linking databases such as in Queensland with their Queensland Colorectal Cancer Database[15, 20], or studying techniques to improve the yield from complete administrative databases[20, 21]. Alternatively, the development of a robust 
prospective registry will allow us to develop future registry based clinical trials[22]. Another major limitation was the lack of individual surgeon data. Distribution and volume of procedures of individual surgeons cannot be determined from administrative data in their current form. Comparing individual surgeon outcomes on ever smaller numbers may seem pointless, but it may provide insight into the impact of subspecialty training of these surgeons in contrast to hospital volume. Such data may be available in datasets such as the BCCA.

\section{Conclusion}

The inpatient mortality after elective rectal cancer surgery in Victoria is low and there is no correlation with hospital volumes. Although individual hospital volumes would not meet many international definitions of high-volume centres, based on mortality alone there is no case for service centralisation. Our data were missing many important oncological outcomes that could be used as quality indicators, and their consideration in the development of future datasets is vital for future service planning, training and innovation.

\section{Acknowledgements}

We would like to thank Chris Brown from Dr Foster, Telstra Health for his work in the interrogation of the VAED and providing statistical support. This project was supported by the Department of Health and Human Services, Victoria.

This article is protected by copyright. All rights reserved. 


\section{References}

1. Munro A, Brown M, Niblock P, Steele R, Carey F: Do Multidisciplinary Team (MDT) processes influence survival in patients with colorectal cancer? $A$ population-based experience. BMC Cancer 2015, 15:686.

2. Optimal care pathway for people with colorectal cancer [www.cancer.org.au/ocp]

3. Chioreso C, Del Vecchio N, Schweizer ML, Schlichting J, Gribovskaja-Rupp I, Charlton ME: Association Between Hospital and Surgeon Volume and Rectal Cancer Surgery Outcomes in Patients With Rectal Cancer Treated Since 2000: Systematic Literature Review and Meta-analysis. Dis Colon Rectum 2018, 61(11):1320-1332.

4. Huo YR, Phan K, Morris DL, Liauw W: Systematic review and a meta-analysis of hospital and surgeon volume/outcome relationships in colorectal cancer surgery. J Gastrointest Oncol 2017, 8(3):534-546.

5. El Amrani M, Clement G, Lenne X, Rogosnitzky M, Theis D, Pruvot FR, Zerbib P: The Impact of Hospital Volume and Charlson Score on Postoperative Mortality of Proctectomy for Rectal Cancer: A Nationwide Study of 45,569 Patients. Ann Surg 2018, 268(5):854-860.

6. Aquina $\mathrm{CT}$, Probst $\mathrm{CP}$, Becerra AZ, lannuzzi JC, Kelly KN, Hensley BJ, Rickles AS, Noyes K, Fleming FJ, Monson JR: High volume improves outcomes: The argument for centralization of rectal cancer surgery. Surgery 2016, 159(3):736-748.

7. Baek JH, Alrubaie A, Guzman EA, Choi SK, Anderson C, Mills S, Carmichael J, Dagis A, Qian D, Kim J et al: The association of hospital volume with rectal cancer surgery outcomes. Int J Colorectal Dis 2013, 28(2):191-196.

8. van Gijn W, Gooiker GA, Wouters MW, Post PN, Tollenaar RA, van de Velde CJ: Volume and outcome in colorectal cancer surgery. Eur J Surg Oncol 2010, 36 Suppl 1:S55-63.

9. Archampong $D$, Borowski D, Wille-Jorgensen $\mathrm{P}$, Iversen $\mathrm{LH}$ : Workload and surgeon's specialty for outcome after colorectal cancer surgery. Cochrane Database Syst Rev 2012(3):CD005391.

10. Jonker FHW, Hagemans JAW, Burger JWA, Verhoef C, Borstlap WAA, Tanis PJ, Dutch Snapshot Research G: The influence of hospital volume on long-term oncological outcome after rectal cancer surgery. Int J Colorectal Dis 2017, 32(12):1741-1747. 
11. Etzioni DA, Young-Fadok TM, Cima RR, Wasif N, Madoff RD, Naessens JM, Habermann EB: Patient survival after surgical treatment of rectal cancer: impact of surgeon and hospital characteristics. Cancer 2014, 120(16):24722481.

12. Porter GA, Soskolne CL, Yakimets WW, Newman SC: Surgeon-related factors and outcome in rectal cancer. Ann Surg 1998, 227(2):157-167.

13. Heriot A, Platell C, Byrne C, Chapuis P, Doudle M, McMurrick P, Murphy E, Thompson-Fawcett $M$, Brennan A, Reid C et al: The Bi-National Colorectal Cancer Audit Report 2018. In., May 2018 edn; 2018.

14. Faragher IG, Hong MK, Stupart D, Watters DA, Yeung J: Complete state-wide outcomes in elective colon cancer surgery. ANZ J Surg 2018, 88(11):11741177.

15. Queensland Colorectal Cancer Audit Report 2016 [https://qccat.health.qld.gov.au/documents/Colorectal Qld.pdf]

16. Burke JP, Coffey JC, Boyle E, Keane F, McNamara DA: Early outcomes for rectal cancer surgery in the republic of ireland following a national centralization program. Ann Surg Oncol 2013, 20(11):3414-3421.

17. The Duke's Club [https://www.thedukesclub.org.uk]

18. Nikolovski Z, Watters DAK, Stupart D, Guest GD: Colorectal multidisciplinary meetings: how do they affect the timeliness of treatment? ANZ J Surg 2017, 87(10):E112-E115.

19. Stewart GD, Long G, Tulloh BR: Surgical service centralisation in Australia versus choice and quality of life for rural patients. Med J Aust 2006, 185(3):162-163.

20. Hong MK, Skandarajah AR, Faiz OD, Hayes IP: How to use administrative data for surgical outcomes in acute diverticulitis. General Surgery 2016, 1(1).

21. MacCallum C, Da Silva N, Gibbs P, Thomson BNJ, Skandarajah A, Hayes I: Accuracy of administrative coding data in colorectal cancer resections and short-term outcomes. ANZ J Surg 2018, 88(9):876-881.

22. James S, Rao SV, Granger CB: Registry-based randomized clinical trials--a new clinical trial paradigm. Nat Rev Cardiol 2015, 12(5):312-316. 
Figure 1

Crude inpatient mortality rates with $95 \%$ confidence intervals, together with corresponding resection volumes in Victoria.

Figure 2

Funnel plot showing the variation in inpatient mortality for the 14 individual hospitals within the select peer group.

Figure 3

Frequency of procedure types divided into the peer group and the remainder of Victoria, July 2012 to June 2016.

\section{Supporting Information}

\section{Supplementary Table 1}

The diagnosis and procedure codes used to define rectal cancer resection cohort. At least one code from each group was required.

This article is protected by copyright. All rights reserved. 


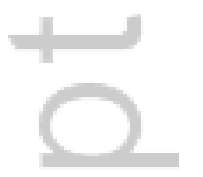

This article is protected by copyright. All rights reserved. 


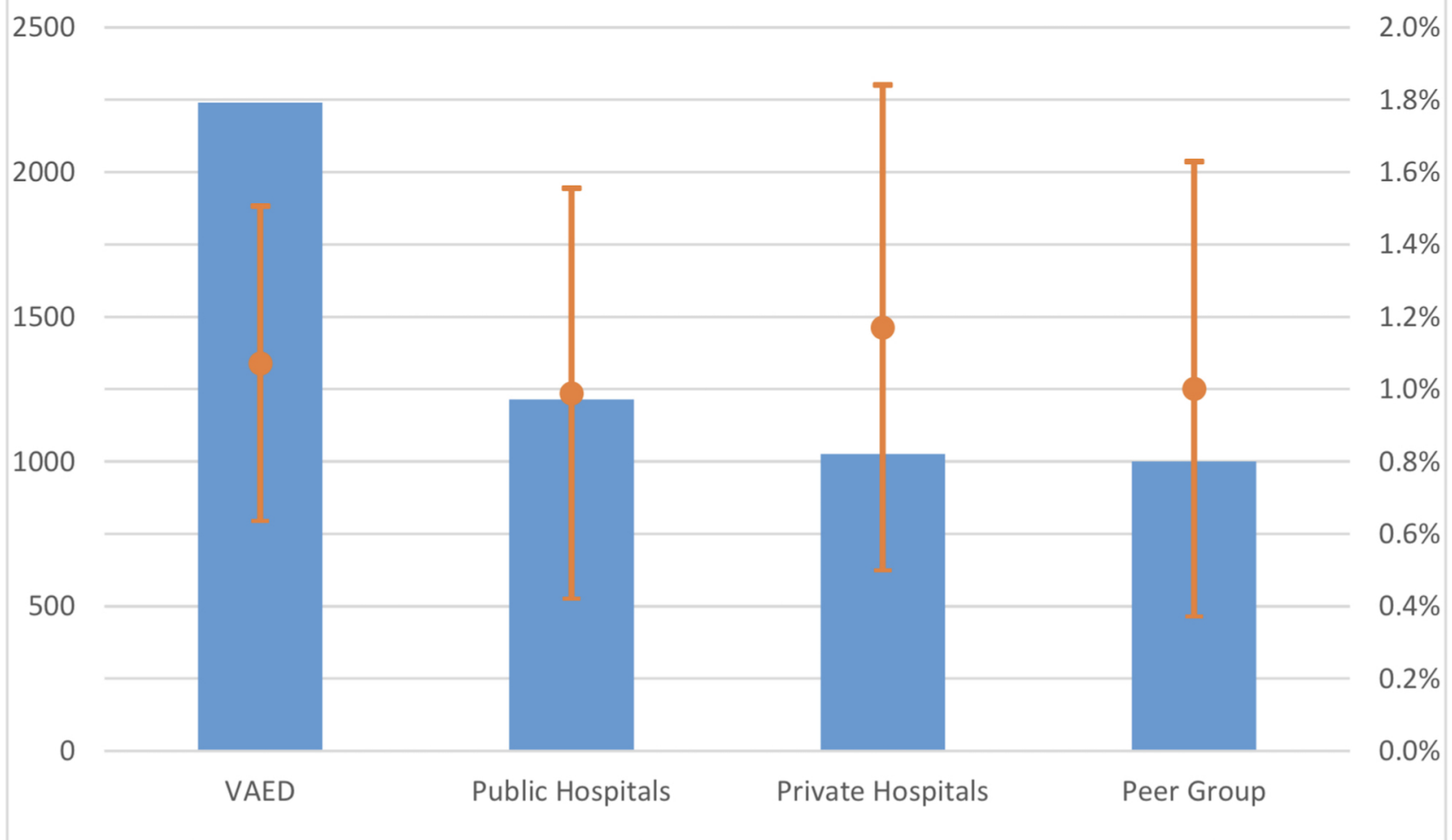

ANS_15546_Figure 1.jpg

This article is protected by copyright. All rights reserved. 


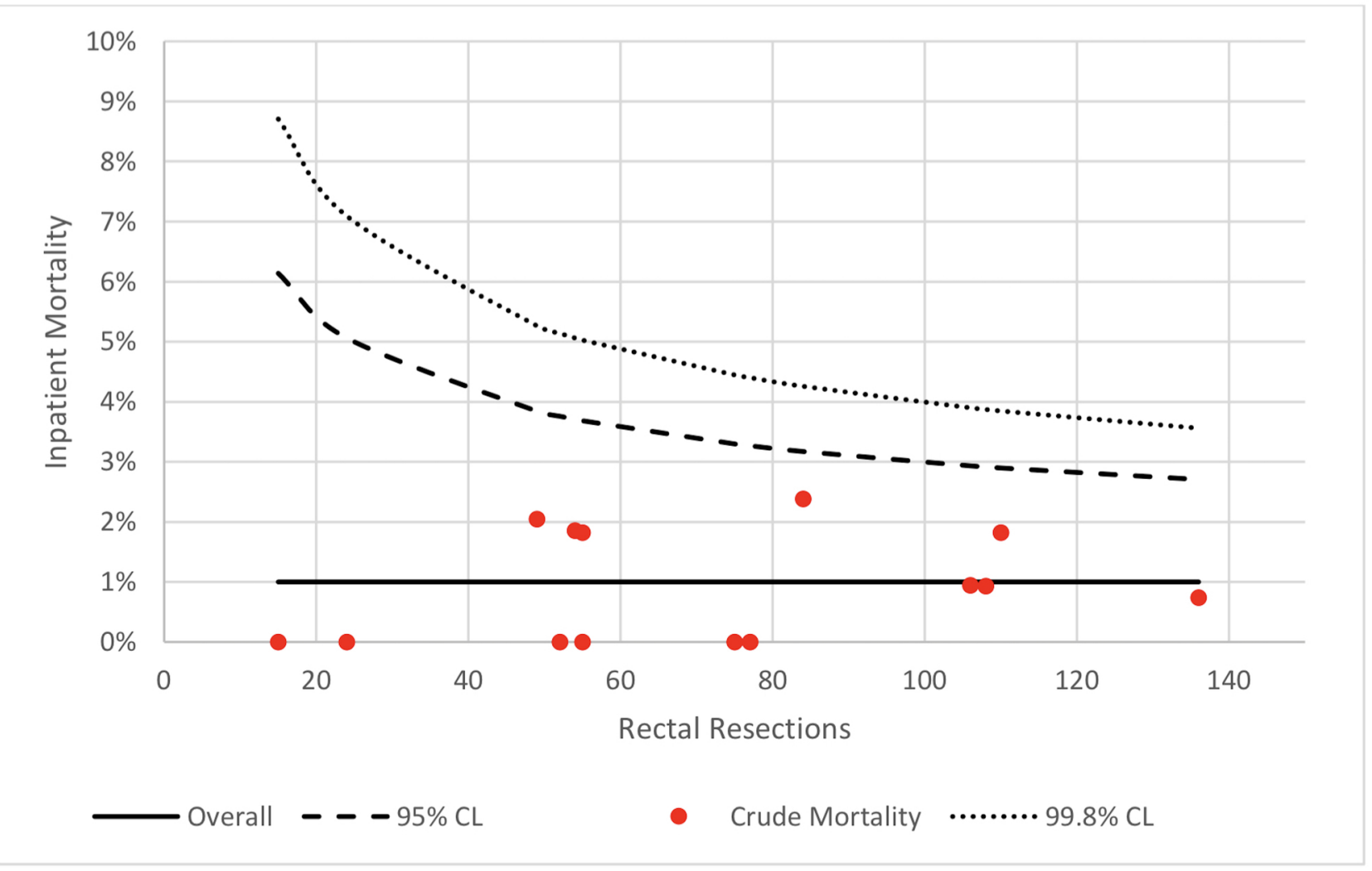

ANS_15546_Figure 2.jpg

This article is protected by copyright. All rights reserved. 


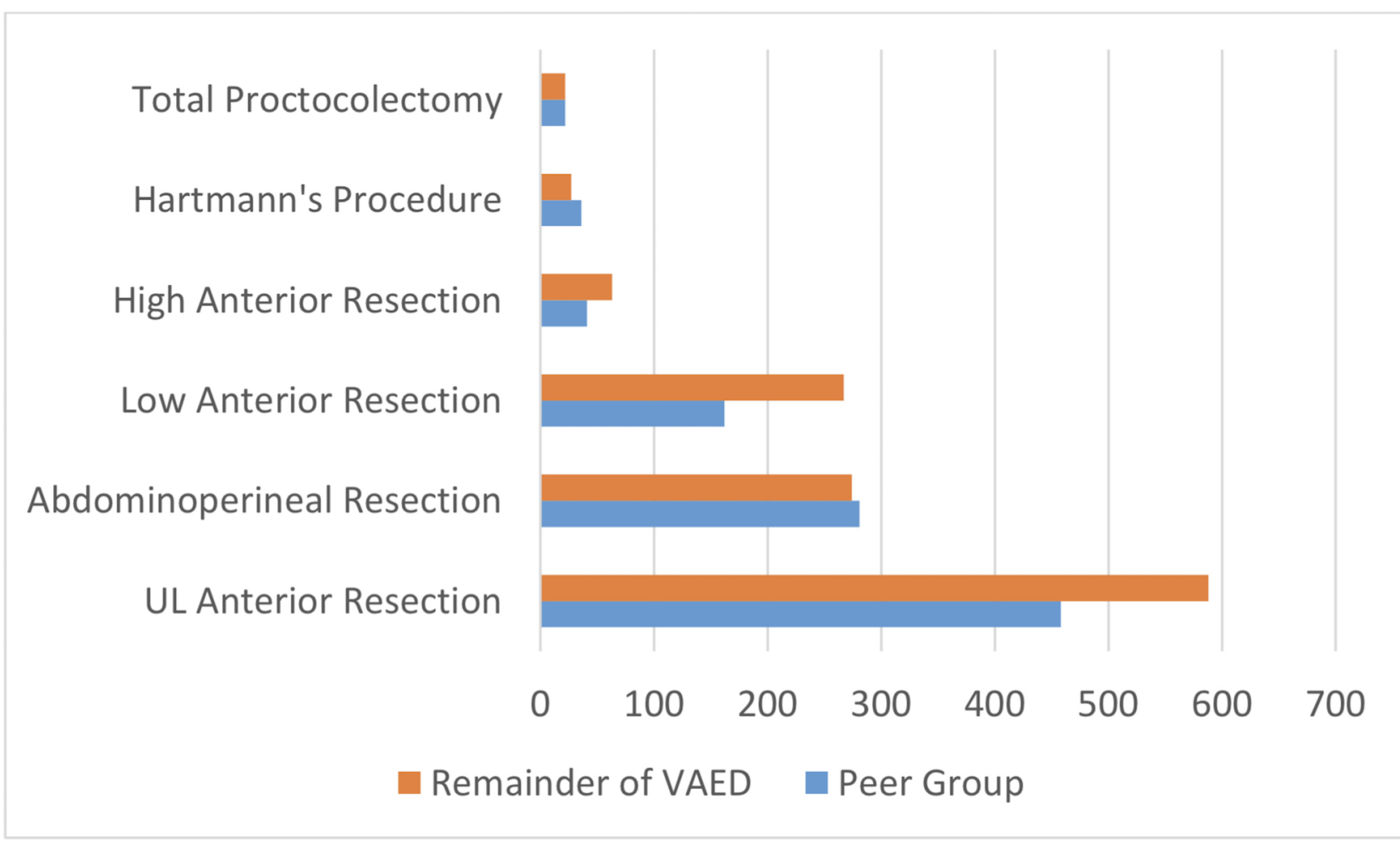

ANS_15546_Figure 3.jpg

This article is protected by copyright. All rights reserved. 


\section{Table 1}

Summary of crude outcomes for elective rectal cancer resections in Victoria, July 2012 to June 2016.

\begin{tabular}{|c|c|c|c|c|c|c|c|c|}
\hline Cohort & $\begin{array}{c}\text { Rectal } \\
\text { Resections }\end{array}$ & Mean Age $( \pm s d)$ & $\%$ Male & $\begin{array}{c}\text { Median } \\
\text { LOS [range] }\end{array}$ & $\begin{array}{l}\text { Inpatient } \\
\text { Mortality }\end{array}$ & $\begin{array}{c}\text { Relative Risk of } \\
\text { Mortality }\end{array}$ & $\begin{array}{c}\text { Prolonged } \\
\text { LOS }\end{array}$ & 30-Day Readmissions \\
\hline VAED & 2241 & $65 \pm 13$ & $63 \%$ & 10 & $24(1.1 \%)$ & $0.45(0.29-0.66)$ & $40 \%$ & $246(11 \%)$ \\
\hline Public Hospitals & 1215 & $64 \pm 13$ & $65 \%$ & $10[6-14]$ & $12(1.0 \%)$ & $0.39(0.20-0.69)$ & $41 \%$ & $180(15 \%)$ \\
\hline Private Hospitals & 1026 & $65 \pm 13$ & $59 \%$ & 11 [6-14] & $12(1.2 \%)$ & $0.52(0.27-0.90)$ & $38 \%$ & $66(6.4 \%)$ \\
\hline Peer Group & 1000 & $64 \pm 13$ & $65 \%$ & $10[8-13]$ & $10(1.0 \%)$ & $0.41(0.19-0.76)$ & $39 \%$ & $149(15 \%)$ \\
\hline
\end{tabular}

This article is protected by copyright. All rights reserved. 


\section{University Library}

\section{- M M N E R VA A gateway to Melbourne's research publications}

Minerva Access is the Institutional Repository of The University of Melbourne

Author/s:

Hong, MK-Y;Yeung, JMC;Watters, DAK;Faragher, IG

Title:

State-wide outcomes in elective rectal cancer resection: is there a case for centralization in Victoria?

Date:

2019-12-04

Citation:

Hong, M. K. -Y., Yeung, J. M. C., Watters, D. A. K. \& Faragher, I. G. (2019). State-wide outcomes in elective rectal cancer resection: is there a case for centralization in Victoria?. ANZ JOURNAL OF SURGERY, 89 (12), https://doi.org/10.1111/ans.15546.

Persistent Link:

http://hdl.handle.net/11343/286712 